\title{
Dielectric properties of saline soil based on a modified Dobson dielectric model
}

\author{
Nigara TASHPOLAT ${ }^{1}$, DING Jianli ${ }^{{ }^{*}}$, YU Danlin ${ }^{2}$ \\ ${ }^{1}$ Key Laboratory of Oasis Ecology, Xinjiang University, Urumqi 830046, China; \\ ${ }^{2}$ Earth and Environmental Studies, Montclair State University, Montclair 07043, USA
}

\begin{abstract}
Soil salinization is a major concern for agricultural development in arid areas. In this paper, a modified Dobson dielectric model was applied to simulate the dielectric constant of saline soil in the Ugan-Kuqa river delta oasis of Xinjiang Uygur autonomous region, northwestern China. The model performance was examined through analyzing the influences of its parameters on the soil dielectric constant and the relationship between radar backscattering coefficient and the dielectric constant of saline soil. The results of the study indicate that: (1) The real part of the soil dielectric constant is affected by soil water content at low radar frequencies; the imaginary part is closely related with both the soil water content and soil salt content. (2) The soil water and salt contents are related with the coefficient of dialectical loss, which is consistent with the natural conditions of saline soil in arid areas and provides valuable references for the study of soil dielectric properties. (3) The changes of soil water content and soil salt content have instant influences on the dielectric constant of saline soil. Subsequently, the radar backscattering coefficient is affected to respond to the dielectric constant of saline soil. The radar backscattering coefficient is most responsible to the radar's cross polarization pattern with a correlation coefficient of $R^{2}=0.75$. This study provides a potential method to monitor soil salinization and soil water content by using a soil dielectric model and radar techniques.
\end{abstract}

Keywords: saline soil; dielectric constant; dielectric constant model; backscattering coefficient; Radarsat-2 images

Citation: Nigara TASHPOLAT, DING Jianli, YU Danlin. 2015. Dielectric properties of saline soil based on a modified Dobson dielectric model. Journal of Arid Land, 7(5): 696-705. doi: 10.1007/s40333-015-0130-0

Soil salinization is one of the most common processes harming soil quality, especially in arid and semi-arid regions (Wang, 1993). It is estimated that salinized land accounts for $4.88 \%$ of the total useable land areas in China, and the percentage is up to $9.40 \%$ in the arid and semi-arid western China. That is to say, more than two-thirds (69.03\%) of China's salinized soil is in the arid and semi-arid regions of the country (Tian et al., 2000).

Apart from salinization due to natural processes, soil salinization is also more likely a process which is affected by increasingly intensive human activities. This is evident in the fact that most fast salinized soils are often found in oasis regions in the arid and semi-arid areas. Such spatial overlapping of soil salinization and human activity in the arid and semi-arid regions points to a potential vicious cycle (Zhao, 1991). On one hand, soil salinization causes further degradation of soil quality hence reduces soil usability and crop productivity. On the other, the reduced land carrying capacity might cause further intensification of human activities hence aggravate future soil salinization. This is especially true in western China under the current regional development strategy of developing the Great West (Ha, 2009). To mitigate further soil salinization, it becomes imperative to develop effective and efficient means that can evaluate, monitor, and possibly forecast soil salinization in arid and semi-arid regions (Dehaan and Taylor, 2002; Dong et al., 2007).

"Corresponding author: DING Jianli (E-mail: watarid@xju.edu.cn) Received 2014-07-03; revised 2014-12-12; accepted 2015-02-06

(c) Xinjiang Institute of Ecology and Geography, Chinese Academy of Sciences, Science Press and Springer-Verlag Berlin Heidelberg 2015 
In recent years, monitoring and evaluating soil salt contents via remote sensing images has become an increasingly useful approach in arid and semi-arid regions (Amezketa, 2006). Many researchers (Qiao, 1996; Saysel and Barlas, 2001; Stasyuk, 2001; He et al., 2004; Shi et al., 2004; Pankova, 2007) have carried out various studies on soil salinization by concentrating on salinization monitoring and modeling. Though in the early stages, visible, infrared and near-infrared spectra have been used to monitor and evaluate soil water and salt contents, they often become much less effective if there are clouds over the study regions (Shi et al., 2002). On the other hand, microwave radar can penetrate clouds rather effortlessly (Bindlish and Barros, 2001). In addition, vegetation scattering models such as water-cloud model (Attema and Ulaby, 1978) and MIMICS model (Ulaby et al., 1990) are often employed to remove the effects of vegetation cover on radar signal, which renders microwave radar to be a primary choice to monitor and evaluate soil water contents. Studies employing microwave radar for soil salt content monitoring and evaluating, however, still remain quite limited. The few available studies focus primarily on conceptual and qualitative discussions (Yang et al., 2003; Davenport et al., 2005; Wang et al., 2005; Wu, 2006).

This study aims to propose a new, more quantified approach to monitor and evaluate soil salt contents in arid and semi-arid regions via microwave radar. The approach is based on the dielectric model of saline soil and the backscattering coefficient of the microwave radar image. According to Shao et al. (2002), the imaginary part of the dielectric constant is closely related with the salt content of saline soil. In the meantime, the backscattering coefficient of the radar image comes as a composite indicator of various soil parameters, and are also parameters used to calculate the dielectric constant. This study hence attempts to build a relationship between the backscattering coefficient of the radar image and the salt contents of saline soil via the dielectric constant. Apparently, being able to accurately identify how the salt content of saline soil is associated with the backscattering coefficient of the radar image requires accurate calculation of the dielectric constant. The traditional dielectric model of- ten fells short for providing proper accuracy to obtain the dielectric constant in arid and semi-arid areas. On the other hand, the corrected dielectric model, i.e. the Dobson dielectric model, seems to give better results.

\section{Study area}

The current study focuses on the Ugan-Kuqa river delta oasis which is located to the south of the Tianshan Mountains and at the north of the Tarim Basin, with geographic coordinates of $41^{\circ} 06^{\prime}-41^{\circ} 38^{\prime} \mathrm{N}$ and $81^{\circ} 26^{\prime}-83^{\circ} 17^{\prime} \mathrm{E}$ (Fig. 1). The climate is very dry with an aridity index of 44.37 and an annual precipitation ranging from 46.4 to $64.5 \mathrm{~mm}$, which is practically negligible compared with the potential evaporation of $1,992-2,863 \mathrm{~mm} / \mathrm{a}$. Precipitation is too scarce to remove the accumulated salt from the soil. The oasis used to have sufficient water resources to support its agricultural development. Situation has changed since the 1970s, however, due to the faster development at the upper reaches of the rivers. An increased use of water has led to the decrease of water resources in the lower reaches. Gradually, the water courses of the rivers dried up; the desert expanded; and the primary vegetation covers degenerated. At present, the oasis has a typical desert vegetation which shows further degradation (Zhang et al., 2009; Ma et al., 2011).

\section{Methods and data processing}

\subsection{The modified Dobson dielectric model}

$\mathrm{Hu}$ (2003) has collected soil samples with five different textures, and produced 150 soil samples with different salt and water contents. Using Microwave network analyzer coaxial probe technique, they measured the dielectric constants of the samples. In addition, basing on the standards generated by the soil texture triangle used by the Department of Agriculture, USA, they calculated the contents, along with soil texture types and other parameters, of differently-sized particles of the soils via the standard measurement methods of soil science (Hu, 2003). The final data were analyzed and used to correct the Dobson model to better fit the saline soil.

The modified Dobson dielectric model of saline soil can be expressed as follows: 


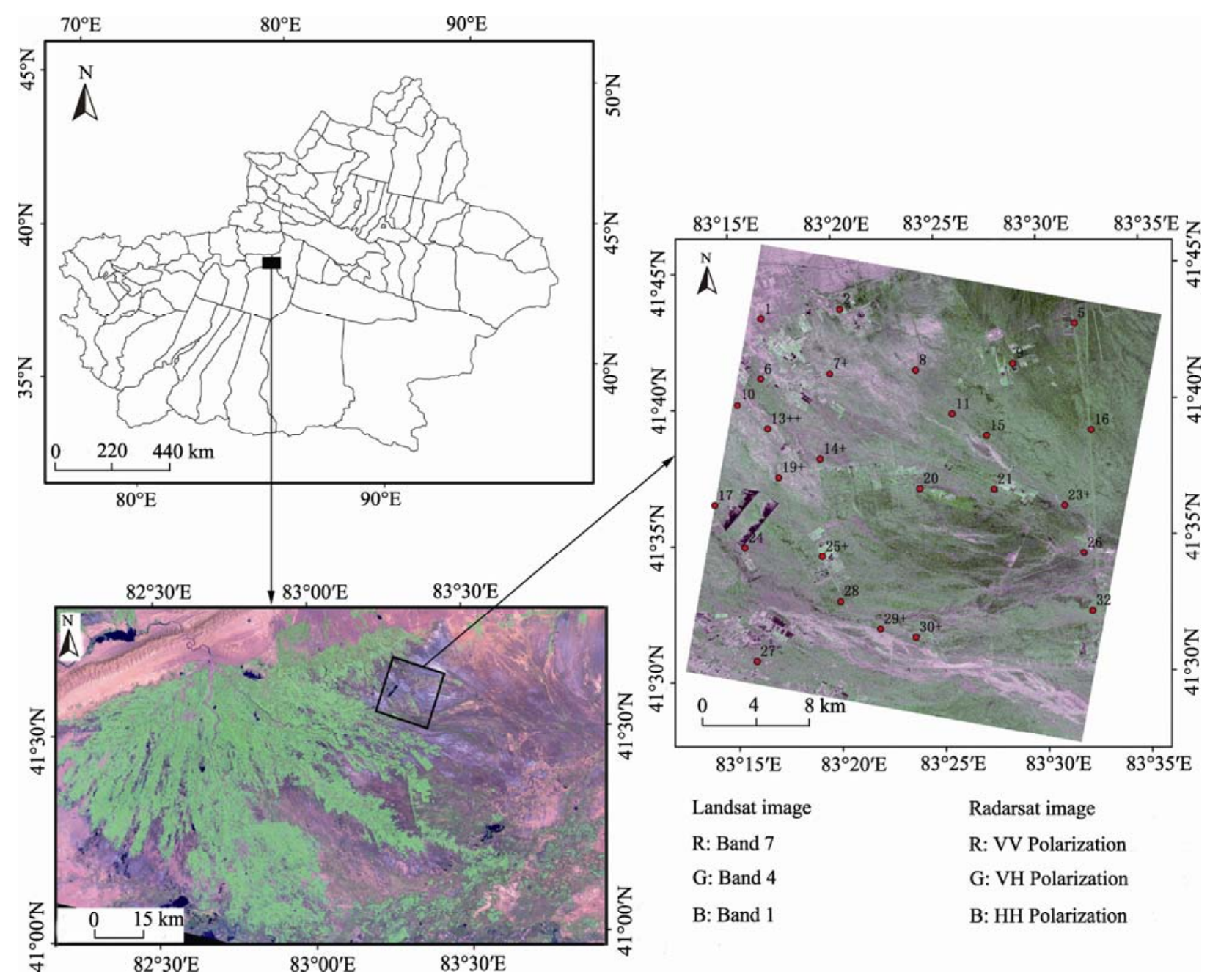

Fig. 1 Landsat 7 image (R:7, G:4, B:1; left) and the distribution of sampling points in a quad-polarization Radarsat image (April 2010; right) of the study area

$$
\left\{\begin{array}{c}
\varepsilon_{m}{ }^{`}=\left[1+\frac{\rho_{b}}{\rho_{s}}\left(\varepsilon_{s}{ }^{\alpha}-1\right)+m_{v}{ }^{\beta}{ }^{{ }^{\prime}} \varepsilon_{f w}{ }^{\alpha}-m_{v}\right]^{1 / \alpha} \\
\varepsilon_{m}{ }^{~} \approx \gamma \cdot m_{v}{ }^{\beta "} / \alpha-2 \frac{S}{f}
\end{array} .\right.
$$

Where $\rho_{s}$ is soil particle density, and is often assigned the value of $2.65 \mathrm{~g} / \mathrm{cm}^{3} ; \rho_{b}$ is soil bulk density; $S$ is soil salt content; $m_{v}$ is volumetric water content; $\alpha$ is the shape factor, and is assigned a value of 0.65 ; and $\beta$ is the combined water correction coefficient, which takes the values:

$$
\begin{aligned}
& \beta_{\varepsilon^{\prime}}=\left(127.48-0.519 S_{\text {and }}-0.512 C_{\text {lay }}\right) / 100 . \\
& \beta_{\varepsilon^{\prime \prime}}=\left(133.797-0.603 S_{\text {and }}-1.66 C_{\text {lay }}\right) / 100 .
\end{aligned}
$$

$\gamma$ is root-mean-square height, and takes the value:

$$
\gamma=\frac{A \xi \chi\left(\rho_{s}-\rho_{b}\right) \rho_{b}}{2 \pi \varepsilon_{0} \rho_{s}} .
$$

Where $A$ is determined by the types of salt ions in the soil solution. For $\mathrm{NaCl}, A$ is usually 1 . $\xi$ is the first order coefficient of electric conductivity and salt content in the Stogrny salt water model (Stogrny, 1971), and it often takes the value of $0.14 ; \varepsilon_{0}$ is the dielectric constant in the vacuum. $S_{\text {and }}$ is sand content of the soil, $C_{\text {lay }}$ is clay content of the soil, and $\chi$ is temperature correction coefficient, expressed as:

$$
\begin{aligned}
\chi=\left[1-1.962 \times 10^{-2} \Delta+8.08 \times 10^{-5} \Delta^{2}-\Delta N\right. \\
\\
\left\{3.02 \times 10^{-5}+3.922 \times 10^{-5} \Delta+N\right. \\
\left.\left.\left(1.721 \times 10^{-5}-6.584 \times 10^{-6} \Delta\right)\right\}\right] .
\end{aligned}
$$


Where $N$ is the ion concentration, and $\Delta=25-\mathrm{t}$.

\subsection{Analysis of the relationships between dielectric model parameters and dielectric constant}

Apparently, the above-mentioned corrected Dobson dielectric model is more suitable to deduce the dielectric constant of saline soil. $\mathrm{Hu}$ (2003) has summarized the various parameters of the five soils with different texture and particle sizes. To analyze the relationships between these parameters of dielectric model and the dielectric constant, we designed the value ranges for other parameters (Table 1). In the meantime, this study focuses on a sandy silt soil, with a sand content of $20.84 \%$ and a clay content of $1.02 \%(\mathrm{Hu}, 2003)$, which resembles closely to soil types in the arid and semi-arid regions. We simulated the soil bulk density with soil temperature $t=26^{\circ} \mathrm{C}$ and $\rho_{b}=1.4 \mathrm{~g} / \mathrm{cm}^{3}$. The real and imaginary parts of the dielectric constant were then calculated via the dielectric model of saline soil. In so doing, we are able to examine the relationships between the model parameters and the dielectric constant.

Table 1 Input parameters of the dielectric model of saline soil

\begin{tabular}{|c|c|c|c|c|c|c|}
\hline & Volumetric water content $(\%)$ & Frequency $(\mathrm{GHz})$ & Salt content $(\mathrm{g} / \mathrm{kg})$ & Soil temperature $\left({ }^{\circ} \mathrm{C}\right)$ & Ion concentration $(\%)$ & Bulk density $\left(\mathrm{g} / \mathrm{cm}^{3}\right)$ \\
\hline Min. & 5 & 0.1 & 1 & -40 & 3 & 0.8 \\
\hline Max. & 95 & 48.0 & 48 & 40 & 75 & 2.0 \\
\hline Step & 5 & 2 & 2 & 5 & 3 & 0.05 \\
\hline
\end{tabular}

\subsection{The backscattering characteristics of saline soil}

Fung et al. (1992) proposed that the backscattering coefficient can be expressed as an Integral Equation Model (IEM) as follows:

$$
\sigma_{p p}^{0}=\frac{k^{2}}{2} e^{-2 k_{z} \sigma^{2}} \sum_{n=1}^{\infty} \sigma^{2 n}\left|I_{p p}^{n}\right|^{2} \frac{W^{n}\left(-2 k_{x}, 0\right)}{n !} .
$$

Where $k$ is space free beam, $k_{z}=k \cos \theta, k_{x}=k \sin \theta$, $W^{\mathrm{n}}\left(-2 k_{x}, 0\right)$ is surface roughness spectrum, $p p$ is polarization pattern, $\sigma^{2}$ is the variance of the surface, and $n$ is scattering term.

In Eq. 6:

$I_{p p}^{n}=\left(2 k_{z}\right)^{n} f_{p p} e^{-\delta^{2} k_{z}^{n}}+\frac{k_{z}^{n}\left[F_{p p}\left(-k_{x}, 0\right)+F_{p p}\left(k_{x}, 0\right)\right]}{2}$.

$F_{p p}\left(-k_{x}, 0\right)+F_{p p}\left(k_{x}, 0\right)$ in Eq. 7 are expressed as follows:

$$
\begin{gathered}
F_{v v}\left(-k_{x}, 0\right)+F_{v v}\left(k_{x}, 0\right)=\frac{2 \sin ^{2} \theta\left(1+R_{v v}\right)^{2}}{\cos \theta} \times \\
{\left[1-\frac{1}{\varepsilon_{r}}+\frac{\varepsilon_{r}-\sin ^{2} \theta-\varepsilon_{r} \cos ^{2} \theta}{\varepsilon_{r}^{2} \cos ^{2} \theta}\right]} \\
F_{h h}\left(-k_{x}, 0\right)+F_{h h}\left(k_{x}, 0\right)=\frac{2 \sin ^{2} \theta\left(1+R_{h h}\right)^{2}}{\cos ^{3} \theta} \times\left(\varepsilon_{r}-1\right), \\
f_{v v}=\frac{2 R_{v v}}{\cos \theta}, f_{h h}=\frac{-2 R_{h h}}{\cos \theta} .
\end{gathered}
$$

$R_{v v}$ and $R_{h h}$ are Fresnel reflectance coefficients of hh and vv polarization, respectively.

$$
\begin{gathered}
R_{v v}=\frac{\varepsilon_{r} \cos \theta-\sqrt{\varepsilon_{r}-\sin ^{2} \theta}}{\varepsilon_{r} \cos \theta+\sqrt{\varepsilon_{r}-\sin ^{2} \theta}} . \\
R_{h h}=\frac{\cos \theta-\sqrt{\varepsilon_{r}-\sin ^{2} \theta}}{\cos \theta+\sqrt{\varepsilon_{r}-\sin ^{2} \theta}} .
\end{gathered}
$$

It can be seen that the dielectric constant is a composite index of soil water, salt content and measuring frequency (Eq. 1). The backscattering coefficient of sample surface is closely related with its Fresnel reflective coefficient, while the latter is directly related with soil dielectric constant (Eq. 6). In this paper, we attempt to first calculate Fresnel reflective coefficient and analyze how it is related with soil water and salt contents through the dielectric constant. Then the relationship will be linked with the backscattering coefficient, hence providing a basis for using microwave radar images to evaluate and monitor soil salt content.

\subsection{Data acquisition and analysis}

The radar image data used in this study are the Radarsat-2 four polarization products. The four polarization modes are $\mathrm{HH}, \mathrm{HV}, \mathrm{VH}$ and VV. The image was acquired on 13 April 2010. In the meantime, the research team collected field data during the same period (the main parameters are reported in Table 2). The Radar band used in this study is the $\mathrm{C}$ band, 
which can penetrate up to $5 \mathrm{~cm}$ under the soil. For this reason, we collected 28 samples at the $0-10 \mathrm{~cm}$ soil depth and extracted soil characteristics as our in situ verification reference. The backscattering coefficient at the sample sites can also be acquired from the four polarization images directly (Fig. 1).

Table 2 Primary parameters of Radarsat-2 system

\begin{tabular}{cccccc}
\hline Band & Polarization mode & Band width & Antenna size & Active antenna & Insulation degree \\
\hline C-Band & HH, HV , VH, VV & $11.6,17.3,30,50,100 \mathrm{MHz}$ & $15.0 \mathrm{~m} \times 1.5 \mathrm{~m}$ & C-Band, T/R module & $>25 \mathrm{~dB}$ \\
\hline
\end{tabular}

Being different from the relative smooth tone of visible, infrared and near-infrared images, however, radar images often contain large amount of white noise, especially when the resolution is fine. The backscattering coefficient of a specific pixel is often an average of the backscattering coefficients of neighboring pixels. In this study, the pixel of the radar image has a resolution of $3.125 \mathrm{~m}$. The backscattering coefficient of the particular pixel is then averaged using pixels that are about $30 \mathrm{~m}$ from the center.

Using soil water and salt contents obtained via fieldwork, we are able to calculate the soil dielectric constant and Fresnel reflective coefficient via the dielectric model of saline soil at the sample sites. A scatterplot of Fresnel reflective coefficient and the backscattering coefficient of the radar image were produced to study the potential relationship between the two.

\section{Results and discussion}

\subsection{Relationship between dielectric constant and volumetric water content}

We simulated the relationships between the dielectric

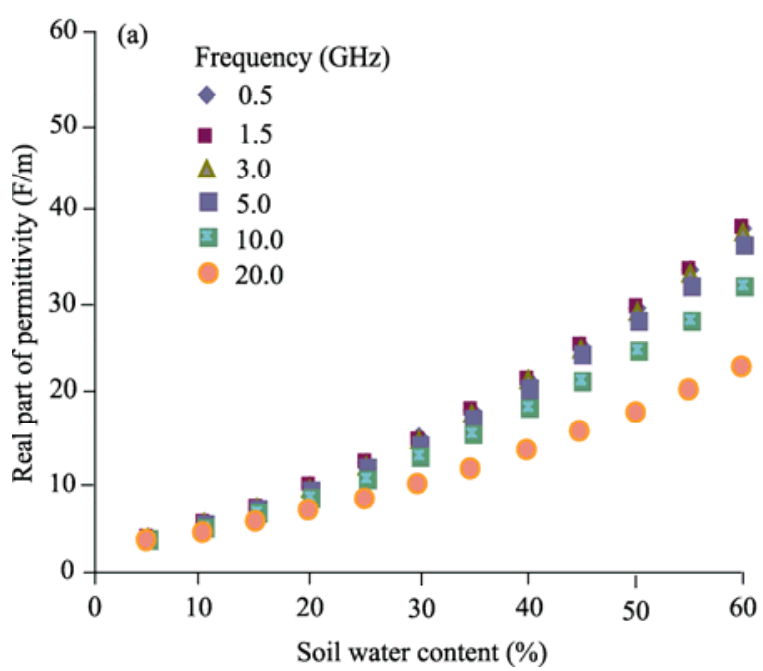

real part of saline soil and volumetric water content under six different frequencies $(0.5,1.5,3.0,5.0,10.0$ and $20.0 \mathrm{GHz}$ ). For the imaginary part, we simulated six different relationships with volumetric water contents under different salt contents $(15,20,25,30,35$ and $40 \mathrm{~g} / \mathrm{kg}$ ). The results are presented in Fig. 2.

Apparently, the real part of soil dielectric constant is most responsive to soil water content under 0.5 $\mathrm{GHz}$ frequency, in which it has the highest curvature (Fig. 2a). As the frequencies increase, the curvature decreases, and reaches the lowest point at $20.0 \mathrm{GHz}$ frequency. The real part of the soil dielectric constant is positively related with soil water content, and follows a typical exponential trend.

Under the same water content, the soil dielectric constant reaches the highest point when salt content reaches $40 \mathrm{~g} / \mathrm{kg}$. This is also where the imaginary part of the dielectric constant is most responsive to volumetric water content (Fig. 2b). As the salt content decreases, the curvature decreases as well, and reaches the lowest point when soil salt content is $15 \mathrm{~g} / \mathrm{kg}$. It is also found that the other model parameters, such as soil sand content, clay content and soil bulk density

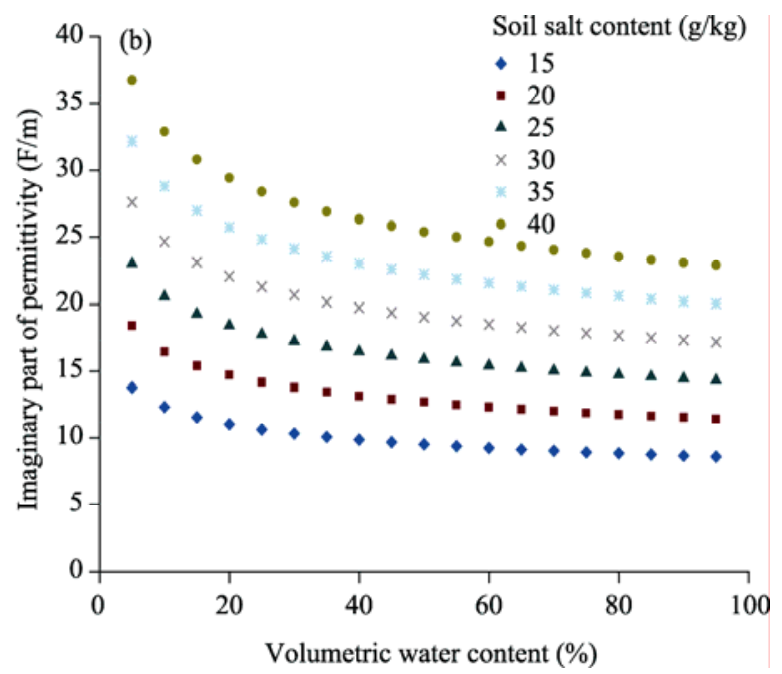

Fig. 2 The relationship between soil water content (a), volumetric water content (b) and dielectric constant 
are also heavily related with the imaginary part. Yet the relationship between the imaginary part and volumetric water content is the most prominent, and also follows a typically negative exponential trend.

\subsection{Relationships between dielectric constant and frequencies}

For the real part of the dielectric constant, we simulated its responses to frequencies under different volumetric water contents (Fig. 3a). For the imaginary part, by setting volumetric water content at $30 \%$ and ion concentration at $0.2 \%$, we simulated its response to frequencies at different salt contents $(10,20,30,40$, 50 and 60 g/kg; Fig. 3b).

The real part of the dielectric constant is most responsive to frequencies when the volumetric water content is $60 \%$ (Fig. 3a). The curvature decreases as the water contents decreases. The other parameters do not seem to have strong influence over the real part. It also suggests that as the frequencies increase, the real part of the dielectric constant decreases (Fig. 3a).
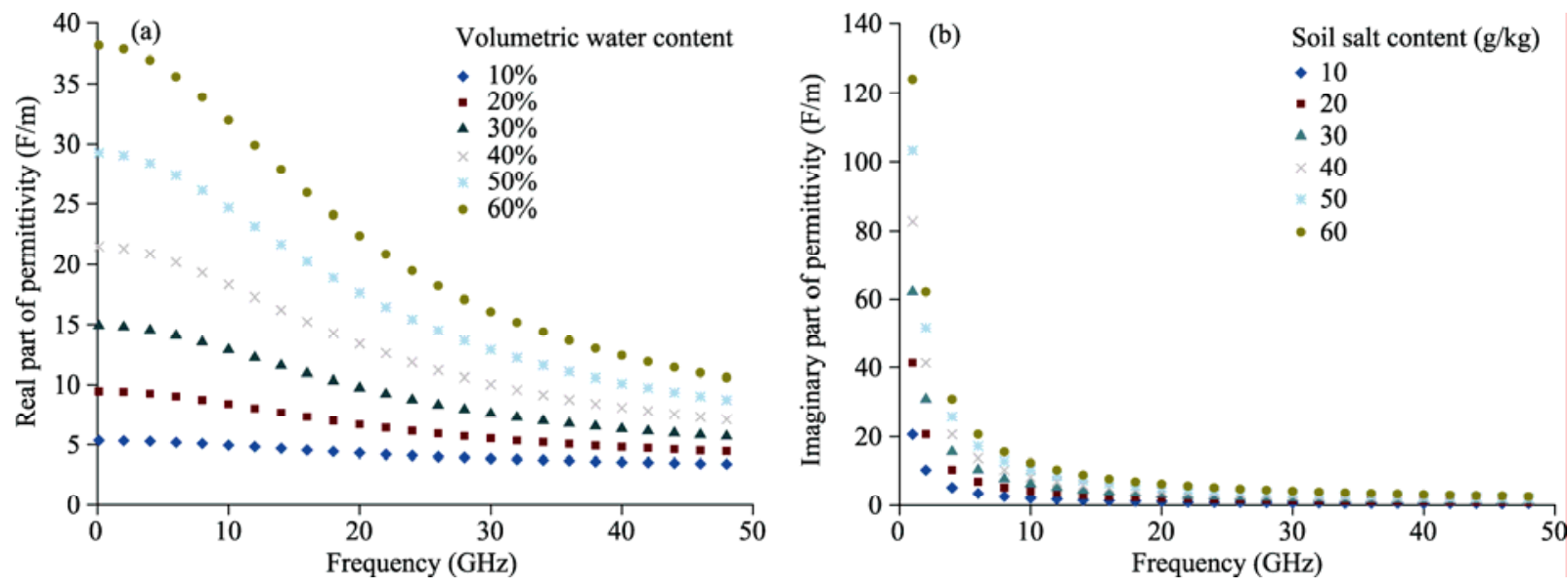

Fig. 3 The relationship between frequency and soil dielectric constant

The imaginary part of the dielectric constant is most responsive to frequencies when soil salt content is at $60 \mathrm{~g} / \mathrm{kg}$, in which the curvature reaches the maximum (Fig. 3b). Along with the increase of frequencies, the response of salt content to the imaginary part of the dielectric constant decreases (Xiong, 2005). Other model parameters (sand, clay contents and soil bulk density) are not quite influential to the imaginary part (not reported here). Figure $3 \mathrm{~b}$ also suggests that the imaginary part of the dielectric constant is often quite high (over 100) at lower frequencies (less than $2.0 \mathrm{GHz}$ ), though it remains within reasonable ranges $(10-40)$ at other frequencies ( $\mathrm{Hu}, 2003)$. As frequencies increase, the imaginary part decreases, which is more so when the soil contains higher levels of salt content.

\subsection{Relationships between dielectric constant and soil temperature}

For the real part of the soil dielectric constant, by set- ting the frequency at $3.0 \mathrm{GHz}$, we simulated its responses to soil temperature at different volumetric water contents $(10 \%, 20 \%, 30 \%, 40 \%, 50 \%, 60 \%$; Fig. 4a). For the imaginary part, by setting the volumetric water content at $30 \%$ and ion concentration at $0.2 \%$, we simulate its responses to soil temperature under different soil salt contents $(10,20,30,40,50$ and 60 g/kg; Fig. 4b).

Figure $4 \mathrm{a}$ indicates that the real part is most responsive to soil temperature when the volumetric water content is $60 \%$. The curvature is the highest, and decreases as the volumetric water content decreases. In addition, when the soil temperature is below zero, as temperature increases, the real part of the dielectric constant increases. Yet the trend reverses itself once the temperature is over zero, with smaller range of fluctuation. We argue that this might be due to the difference of dielectric constant for water and ice. Since the dielectric constant of water (80.0) is far greater than that of ice (3.15), there is a large amount 

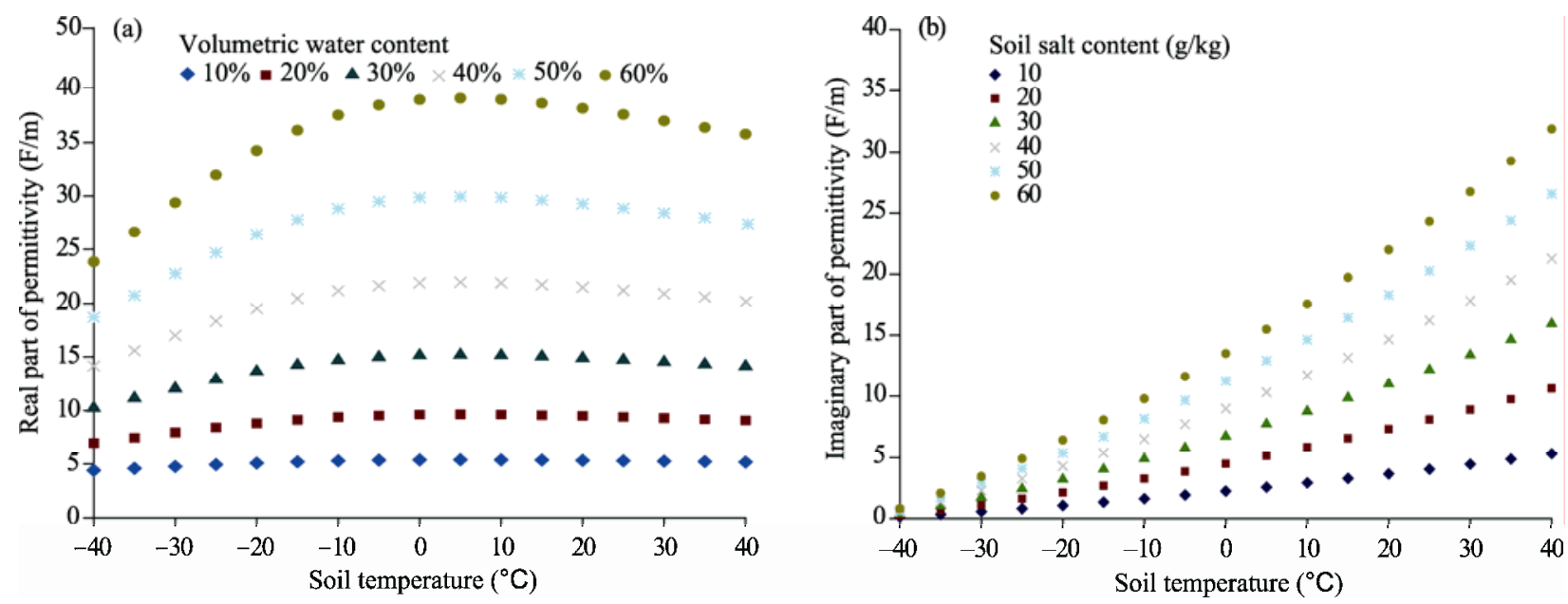

Fig. 4 The relationship between soil temperature and soil dielectric constant

of ice in the soil when the soil temperature is below zero. As soil temperature increases, part of the ice gradually melts to become water, which leads to an increase in the real part of the dielectric constant, especially when the soil temperature is near zero and the water content increases drastically. Once the soil temperature is above zero, the real part of the dielectric constant decreases as temperature increases, though at a slower pace. This could be because that higher soil temperatures enable water to contain higher levels of soluble salt, hence reduce the real part of the dielectric constant.

Figure $4 \mathrm{~b}$ suggests that the imaginary part of the dielectric constant is most responsive to soil temperature at higher salt contents, and reaches the highest in our simulation when the salt content is $60 \mathrm{~g} / \mathrm{kg}$. It also indicates that the increase of soil temperatures (regardless of it being below or above zero) causes an increase in the imaginary part of the dielectric constant, and the relationship shows a typical exponential trend.

\subsection{Relationships between dielectric constant and soil salt content}

Soil salt content mainly influences the imaginary part of the dielectric constant (Eq. 1). This is also one of the primary reasons why the dielectric constant model was used to study saline soil. We simulated the relationships between the imaginary part and soil salt content under different frequencies (Fig. 5).

The results agree well with the common recognition that under the same salt content, the imaginary part of

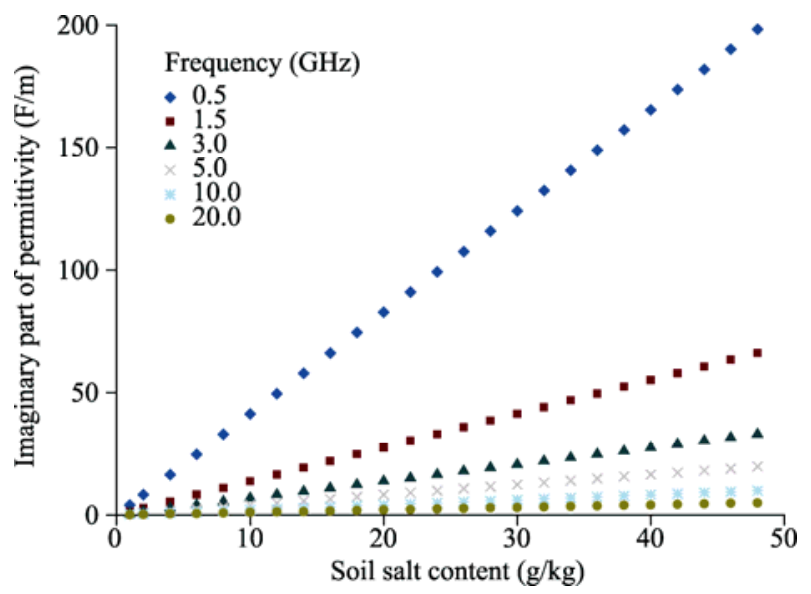

Fig. 5 The relationship between soil dielectric constant and soil salt content

the soil dielectric constant is the highest at lower frequencies. The curvature decreases as the frequencies decrease. In addition, other than at $0.5 \mathrm{GHz}$ frequency, the relationships between the imaginary part and soil salt content are rather reasonable, especially at 1.5, 3.0 and $5.0 \mathrm{GHz}$ frequencies. It almost follows a linear relationship with higher salt contents incurring higher imaginary part of the dielectric constant.

\subsection{Relationships among other parameters and dielectric constant}

Further analyses suggest that soil bulk density and ion concentration are also influential over the dielectric constant of soil, though less salient than soil water and salt contents. To keep the writing concise, we won't list all the results here. In addition, the real and imaginary parts of the dielectric constant remain rela- 
tively stable within the soil temperature range of $0-20^{\circ} \mathrm{C}$, which is common under natural conditions (Fig. 3). In this regard, we conclude that it is fairly reasonable to study soil water and salt contents via the dielectric constant model of saline soil.

\subsection{Relationship between Fresnel reflective coef- ficient and backscattering coefficient}

From field work and laboratory measurements, we plotted Fresnel reflective coefficient of saline soil and the radar backscattering coefficient of the sample sites under the four aforementioned polarization modes (Fig. 6). Figure 6 indicates that the two are mostly positively related. Since Fresnel reflective coefficient is a function of dielectric constant (positive), we argue that the increase of the latter might cause the former to increase as well. The changing range, however, remains relatively small, often within 20 .

Furthermore, it seems that the relationships between Fresnel reflective coefficient and radar backscattering coefficient are strongest at $\mathrm{HV}$ and $\mathrm{VH}$ polarization models. Under the other two modes, the relationships are less obvious. This result suggests that under the cross-polarization modes ( $\mathrm{HV}$ and $\mathrm{VH})$, radar backscattering coefficient is probably a better predictor for the dielectric constant of saline soil, while it is less effective under the other two modes.
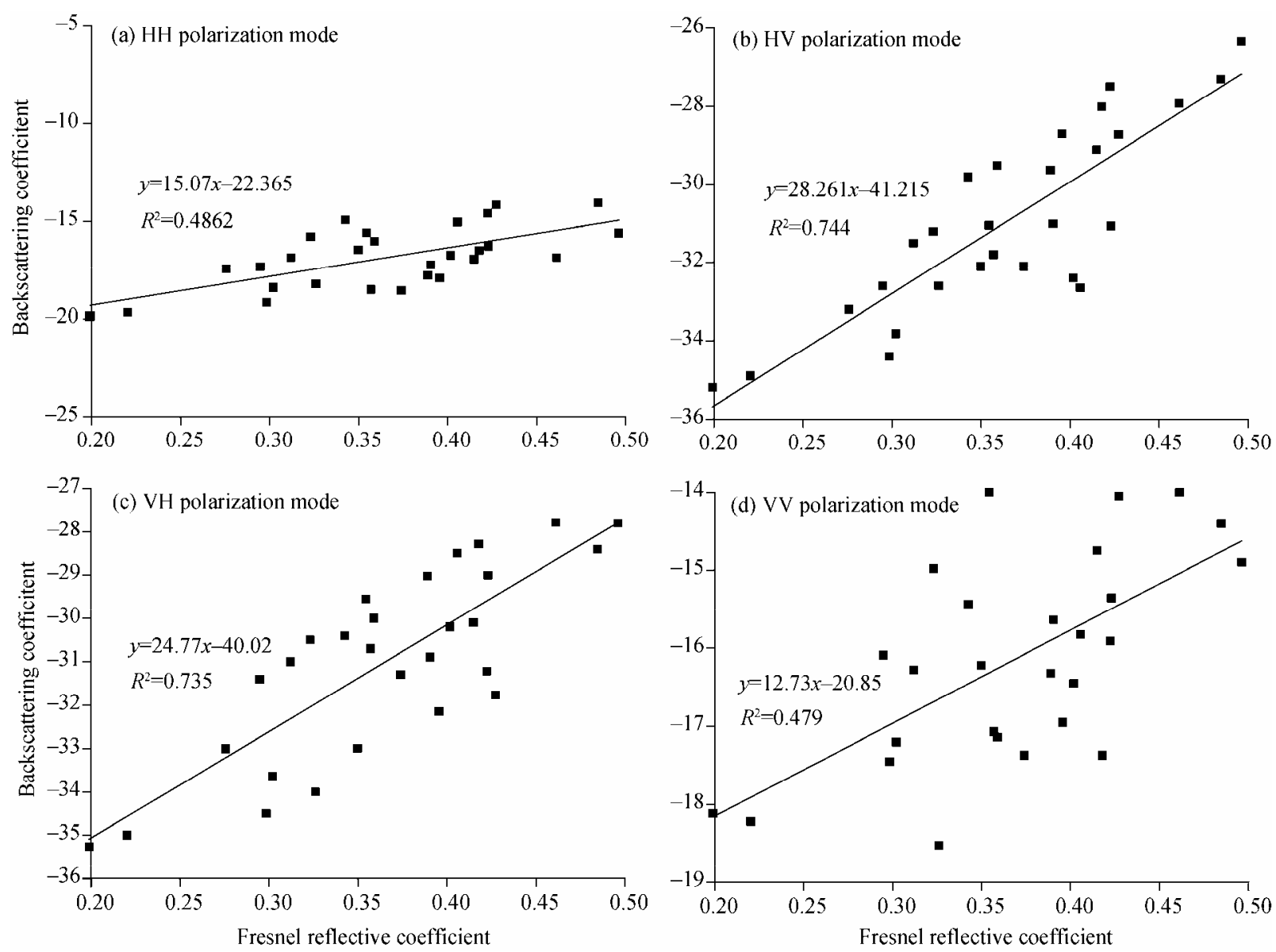

Fig. 6 The relationships between backscattering coefficient and Fresnel reflective coefficient under different polarization modes

\section{Conclusion}

The real part of the soil dielectric constant responds reasonably well to volumetric water content at lower radar frequencies, and the imaginary part is highly correlated to not only soil water contents but also soil salt content. The use of soil dielectric model might be an effective approach to monitor and evaluate soil salt content and soil salinization processes. The experiment and simulation results suggest that the dielectric 
constant agrees well with soil salt contents when soil water content is about $10 \%-40 \%$. Hereby, using soil dielectric properties would be of particular value in studying soil salt content and soil salinization in arid and semi-arid regions where soil water contents are relatively low.

Moreover, our study suggests that the relationships among soil dielectric constant, soil water and salt contents can be further explored via radar images. The backscattering coefficient that can be derived from the latter is strongly related with Fresnel reflective coefficient (especially under the cross-polarization radar images), which is again strongly related with soil salt contents. The results demonstrate the potential of using radar images to monitor and evaluate soil salinization processes in arid and semi-arid regions.

Our study investigated the relationships between the soil dielectric constant and soil salt and water contents. We didn't, however, explore the possibility of estimating soil salt content via the corrected dielectric model. The task apparently merits further discussion. The immediate next step would be to establish a soil salt estimation model using various data sources including optical, microwave and electromagnetic remote sensing techniques. In addition, we also noticed that other factors, i.e. vegetation cover, local terrain, surface texture, etc., might play important roles in determining soil backscattering coefficient. Future studies shall focus on separating these influences and singling out the relationship between backscattering coefficient and soil salt content.

\section{Acknowledgements}

The study was supported by International Science \& Technology Cooperation Program of China (2010DFA92720-12), the Xinjiang Regional Youth Scientific-technical Talent Training Engineering Project (2013711014), the National Natural Science Foundation of China (U1303381, 41261090, 41130531) and the New Century Excellent Talents Supporting Plan of the Ministry of Education of China (NCET-12-1075).

\section{References}

Amezketa E. 2006. An integrated methodology for assessing soil salinization, a pre-condition for land desertification. Journal of Arid Environments, 67(4): 594-606.

Attema E P W, Ulaby F T. 1978. Vegetation modeled as a water cloud. Radio Science, 13(2): 357-364.
Bindlish R, Barros A P. 2001. Parameterization of vegetation backscatter in radar-based, soil moisture estimation. Remote Sensing of Environment, 76(1): 130-137.

Davenport I J, Fernandez G J, Gurney R J. 2005. A sensitivity analysis of soil moisture retrieval from the Tau-Omega microwave emission model. IEEE Transactions on Geoscience and Remote Sensing, 43(6): 1304-1316.

Dehaan R L, Taylor G R. 2002. Field-derived spectra of salinized soils and vegetation as indicators of irrigation-induced soil-salinization. Remote Sensing of Environment, 80: 406-417.

Dong X G, Zhou J L, Chen Y B. 2007. Water and Salt Monitoring in Arid Inland Areas: Model and Application. Beijing: Science Press, 1-27. (in Chinese)

Fung A K, Li Z, Chen K S.1992. Backscattering from a randomly rough dielectric surface. IEEE Transactions on Geoscience and Remote Sensing, 30(2): 356-369.

Ha X P. 2009. Remote sensing-based monitoring model for soil salinization in arid areas. MSc Thesis. Urumqi: Xinjiang University. (in Chinese)

He Y F, Zhang B, Ma C Q. 2004. Study on dynamic change of land sali-alkalization in Songnen Plain - a case study in Nongpan county. Journal of Soil and Water Conservation, 18(3): 146-153. (in Chinese)

$\mathrm{Hu}$ Q R. 2003. Studies on microwave dielectric behavior of moist salt soil and inversion of the moisture and salt content. PhD Dissertation. Beijing: Institute of Remote Sensing Application, Chinese Academy of Sciences. (in Chinese)

Ma X D, Chen Y N, Zhu C G, et al. 2011. The variation in soil moisture and the appropriate groundwater table for desert riparian forest along the lower Tarim River. Journal of Geographical Sciences, 21(1): $150-162$.

Pankova E I. 2007. A new monograph on salt-affected soils and salinization dynamics in the Terek River delta. Eurasian Soil Science, 40(1): 99-100.

Qiao Y L.1996. An application of aerial remote sensing to monitor salinization at Xinding Basin. Advances in Space Research, 18(7): 133-139.

Saysel A K, Barlas Y. 2001. A dynamic model of salinization on irrigated lands. Ecological Modelling, 139(2-3): 177-199.

Shao Y, Lu Y, Dong Q, et al. 2002. Study on soil microwave dielectric characteristic as salinity and water content. Journal of Remote Sensing, 6(6): 423-428. (in Chinese)

Shi J C, Chen K S, Li Q, et al. 2002. A Parameterized surface reflectivity model and estimation of bare surface soil moisture with L-band radiometer. IEEE Transactions on Geoscience and Remote Sensing, 40(12): 2674-2686.

Shi X X, Wang J, Ren C Y, et al. 2004. Study on the modeling of soil salinization in semi-arid area based on GIS and Geo-CA model. Journal of Northeast Normal University, 36(2): 88-94. (in Chinese)

Stasyuk N V. 2001. Temporal dynamics of soil cover salinization in the Terek delta. Russian Journal of Ecology, 32(1): 22-28.

Tian C Y, Zhou H F, Liu G Q. 2000. The proposal on control of soil salinizing and agricultural sustaining development in 21 's century in Xinjiang. Arid Land Geography, 23(3): 178-181. (in Chinese) 
Ulaby F T, Sarabandi K, McDonald K, et al. 1990. Michigan microwave canopy scattering model. International Journal of Remote Sensing, 11(7): 1223-1253.

Wang Z Q. 1993. China Salinity Soil. Beijing: Science Press, 400-515. (in Chinese)

Wang J M, Shi J C, Shao Y. 2005. Soil moisture content monitoring based on ERS wind scatterometer data. Journal of China University of Mining and Technology, 15(4): 305-308.

Wu S L. 2006. Simulation of a combined passive/active microwave remote sensing approach for soil moisture retrieval. Proceedings of the Third International Symposium on Future Intelligent Earth Observation Satellites. Beijing: Science Press, 305-308. (in Chinese)

Xiong W C. 2005. Studies on microwave dielectric behavior of moist salt soil and inversion of the moisture and salt content. MSc Thesis. Beijing: Institute of Remote Sensing Application, Chinese Academy of Sciences. (in Chinese)

Yang H, Shi J, Li Z, et al. 2003. Temporal and spatial soil moisture change pattern detection using multi temporal Radarsat SCANSAR images. Proceedings of IGRASS, IEEE, 2: 1420-1422.

Zhang J X, Liu Z J, Sun X X. 2009. Changing landscape in the three gorges reservoir area of Yangtze River from 1977 to 2005: land use/land cover, vegetation cover changes estimated using multi-source satellite data. International Journal of Applied Earth Observation and Geoinformation, 11(6): 403-412.

Zhao Q G. 1991. Land degradation and its control. China Land Science, 5(2): 22-25. (in Chinese) 